\title{
Variable Speed Asynchronous Generator
}

\author{
Vít BRŠLICA ${ }^{1}$ \\ ${ }^{1}$ Department of Electrical Engineering and Electronics \\ Military Academy in BRNO \\ Kounicova 65, CZ 61200 Brno, Czech Republic \\ phone:+420 973442 319, fax:+420 973442 888, e-mail: vit.brslica@vabo.cz
}

\begin{abstract}
The variable speed power generation brings higher efficiency and other economy benefits namely in low power range sources and isolated systems with local net supply. Typically it is in mobile power generation based on fuel engine drive, but the results are also useful in the area of wind power generation and maybe in few years in automobile industry for car board-net supply as well. To keep high efficiency, the cheap constant-geometry wind turbine must be operated at variable rotation speed in dependence on wind speed. Permanent magnet synchronous generator was first to used in VSCF generation, but its flux cannot be decreased at reduced load, therefore its excellent rated efficiency is not so optimal in competition with much cheaper and robust asynchronous generator (AG) at partial load. The mathematical model for AG optimal slip estimation from efficiency point of view is created. Some model results are presented to show the AG efficiency at varying load and its other advantages.
\end{abstract}

\section{Key words}

Variable speed constant frequency (VSCF) technology, permanent magnet synchronous generator (PMSG), asynchronous generator (AG), efficiency optimization, inverter

\section{Introduction}

Variable speed power generators are used in wind power plants and in new mobile Diesel GEN-SETS [1], [2], where the output power grows with speed. The torque is approximately constant - Diesel, or growing with speed wind turbine. In such applications synchronous generator with permanent magnet field (PMSG) is mostly used because of its best efficiency and no need of field control or supply. Power electronics frequency converter must always complement it (Fig.1), to get constant voltage and frequency at the terminals. Asynchronous generator AG for variable speed was few years ago out of reality, because it needs for each frequency different value of parallel capacitor in autonomous run. New converter techniques with active rectifier bring back the idea of use the cheap, simple and robust AG in power generating at variable speed. Inverter control for AG also can be more simple and not so expensive as for SG, because the synchronism is not strictly necessary.

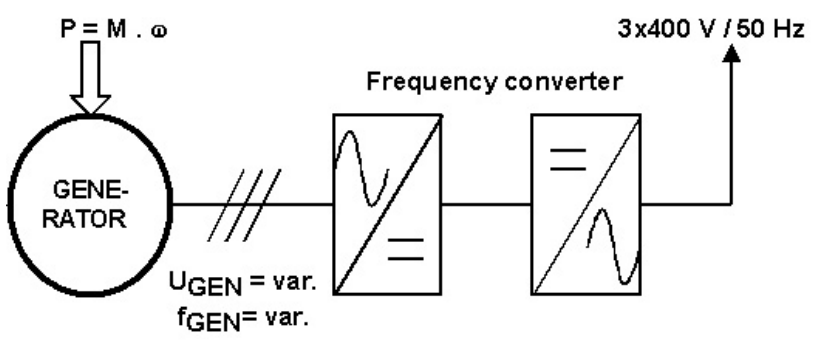

Fig. 1 Block scheme of VSCF (variable speed constant frequency) generating set with indirect - voltage type frequency converter

The road vehicles board net generators are supposed to deliver constant power (maximal) at any speed. Torque is therefore inversely proportional to the speed, and flux should be decreased with the speed grow to keep constant voltage. PMSG is absolutely unsuitable here, because modern engines very wide speed range brings enormous voltage variation at constant field.

The wound rotor SG is therefore used nowadays, with field coil supplied from electronic controller by brushes. The advantage is low-power DC controller for field coil circuit. Stator winding supplies battery (and all the net) via diode bridge rectifier (e.g. DC output). Brush-less generator offers higher reliability and the robust cage rotor $\mathrm{AG}$ with integrated $\mathrm{AC} / \mathrm{DC}$ inverter can replace actual alternator with its field controller and rectifier [3], at minimally equal efficiency and better reliability.

\section{Industrial frequency power sources}

The typical arrangement of variable speed generating set for constant frequency output is in the Fig.1. Not supposing the use of a commutator AC machine (Winter - Eichberg), the frequency converter is obligatory. Such configured power source with constant frequency $(50 \mathrm{~Hz})$ and voltage $(400 \mathrm{~V})$ output is supposed to 
produce more power with growing speed [4]. On the terminals of generating set it appears as the current growup indeed, but in generator with constant flux (magnetic product) the grow of power is given by voltage increase and the current keeps on constant (Table I).

TABLE I. Diesel-driven generator with constant flux, $2 \mathrm{p}=12$

\begin{tabular}{|l|l|l|l|l|l|l|}
\hline Diesel speed n & {$[$ r.p.m. } & 1000 & 1500 & 2000 & 2500 & 3000 \\
\hline $\mathrm{f}_{\text {GEN }}$ & {$[\mathrm{Hz}]$} & 100 & 150 & 200 & 250 & 300 \\
\hline $\mathrm{U}_{\text {GEN }}$ & {$[\mathrm{V}]$} & 140 & 210 & 280 & 350 & 420 \\
\hline $\mathrm{P}$ & {$[\mathrm{W}]$} & 2000 & 3000 & 4000 & 5000 & 6000 \\
\hline $\mathrm{I}_{\text {GEN }}$ & {$[\mathrm{A}]$} & 10 & 10 & 10 & 10 & 10 \\
\hline $\mathrm{I}_{\text {OUT }}$ & {$[\mathrm{A}]$} & 3,3 & 5 & 6,6 & 8,3 & 10 \\
\hline
\end{tabular}

Constant flux with growing frequency makes the iron losses increase and that is why the maximal frequency should not exceed $400 \mathrm{~Hz}$ to keep efficiency and temperature-rise in good values, or to use no iron armature construction.

\section{A. Wind power generation}

If the driving torque grows up with the speed, typically in wind power generating, the generator current must grow too, as is clearly visible in Table II. The generator armature winding wire is then designed from the maximal power (and torque) value and at lower speeds is not fully electrically charged.

TABLE II. Wind turbine driven generator with constant flux

\begin{tabular}{|l|l|l|l|l|l|l|l|}
\hline $\begin{array}{c}\text { Wind speed } \\
\mathrm{V}\end{array}$ & {$[\mathrm{m} / \mathrm{s}]$} & 4 & 6 & 8 & $10]$ & 12 & 14 \\
\hline $\mathrm{f}_{\text {GEN }}$ & {$[\mathrm{Hz}]$} & 80 & 120 & 160 & 200 & 240 & 280 \\
\hline $\mathrm{U}_{\text {GEN }}$ & {$[\mathrm{V}]$} & 120 & 180 & 240 & 300 & 360 & 420 \\
\hline $\mathrm{P}$ & {$[\mathrm{kW}]$} & 1 & 3,38 & 8 & 15,63 & 27 & 42,88 \\
\hline $\mathrm{I}_{\text {GEN }}$ & {$[\mathrm{A}]$} & 6 & 13,5 & 24 & 37 & 54 & 73 \\
\hline $\mathrm{I}_{\text {OUT }}$ & {$[\mathrm{A}]$} & 1,7 & 5,7 & 13,7 & 26,5 & 46 & 73 \\
\hline
\end{tabular}

\section{AG generator}

Till now there is no difference between the use of PMSG or AG respectively. AC/DC converter for PMSG can be more simple, because PM creates the field lastingly, but AG must be first magnetized by stator winding current, therefore diode rectifier cannot be used on its terminals. If two identical inverter units are used as shown in Fig.2, AG can be used for variable speed generation successfully [5].

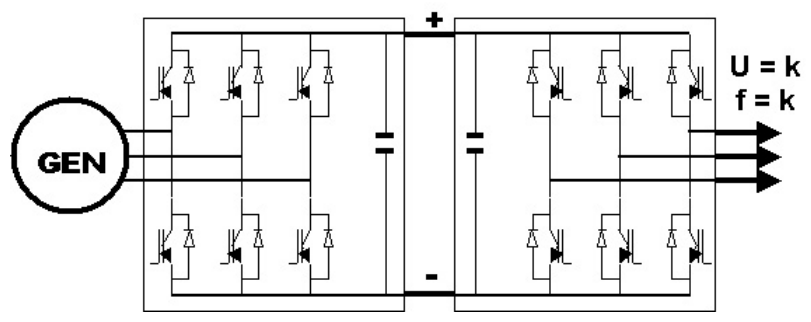

Fig.2 Frequency converter from two identical inverter bridges
Let us suppose that there is in Fig.2 the electrical controlled drive supplied from the terminals on the right side, where voltage and frequency are constant and generator is in motor function starting Diesel. After Diesel starts up, it changes from the load into the source of torque and power and it begins to drive the generator. Modern converter "active front end" [6] with two identical bridge units is able to change its operating quadrant and to deliver the energy "back" into the AC net (recuperation). At any generator speed and voltage, its energy can be inverted to the standard net parameters $(400 \mathrm{~V}, 50 \mathrm{~Hz})$.

If there is no $\mathrm{AC}$ net in isolated systems, some other voltage source must be at disposal for charging of intercircuit capacitors to start the inverter.

For the reverse power flow (from the terminals to AG), the frequency converter is known as a typical converter for $\mathrm{AC}$ drives with voltage inter-circuit. In the constant torque control area (under rated frequency) the magnetic flux in $A G$ is kept on the nearly constant value ( $U / f=k)$. This kind inverter control for the SG must be more accurate, synchronized with rotor position and for correct function it needs the expensive sensor - resolver. Inverter control for the AG is much more simple, because at any frequency which gives non-zero slip the torque $M$ appears.

\section{A. $\quad$ Variable speed $A G$}

Torque is voltage and slip dependent according to the formula:

$$
M=\frac{3 \cdot\left(R_{2}^{\prime} / s\right)}{\omega_{1}} \cdot \frac{U_{1}^{2}}{\left(R_{1}+\left(R_{2}^{\prime} / s\right)\right)^{2}+X_{K}^{2}}
$$

where the slip $\mathrm{s}$ is described by formula:

$$
s=\frac{\omega_{1}-\omega}{\omega_{1}}
$$

The synchronous speed is:

$$
\omega_{1}=2 \pi f_{1} / p
$$

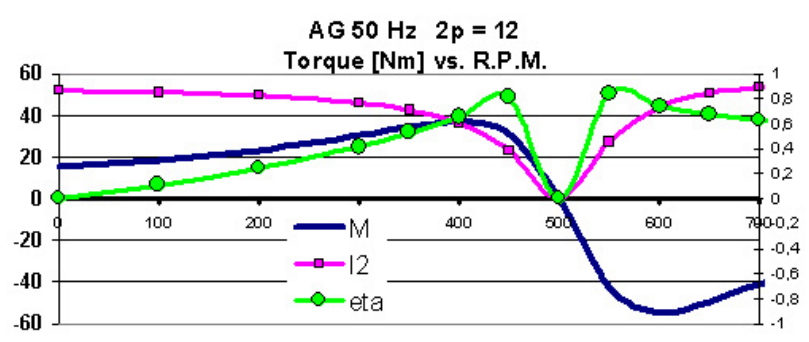

Fig. 3 The 12-pole, 3-ph. AM model for equivalent circuit parameters: $\mathrm{R} 1=\mathrm{R} 2^{\prime}=0,1 \Omega, 2 \pi \mathrm{Lk}=0,01 \mathrm{H}$

From the basic theory it is well known the phenomena, which appears if the AM speed increases over the synchronous one

$$
\omega>\omega_{1}
$$

The slip is negative

$$
\mathrm{s}<0
$$

and the torque, which occurs, is negative too (Fig.3). If the $A G$ is connected with the net, which can supply its magnetizing current (to create the magnetic field), it is 
able to deliver the electric power, or in autonomous run the local capacitor can be a reactive power source [7].

The complete AC/AC converter represents on the AG terminals the supplied variable frequency net. At any speed of AG can be found such frequency, which is "over-synchronous":

$$
f=\frac{n \cdot p}{60(1-s)}
$$

because

$$
\mathrm{n}=\frac{60 f}{\mathrm{p}} \cdot(1-\mathrm{s})[\mathrm{RPM}]
$$

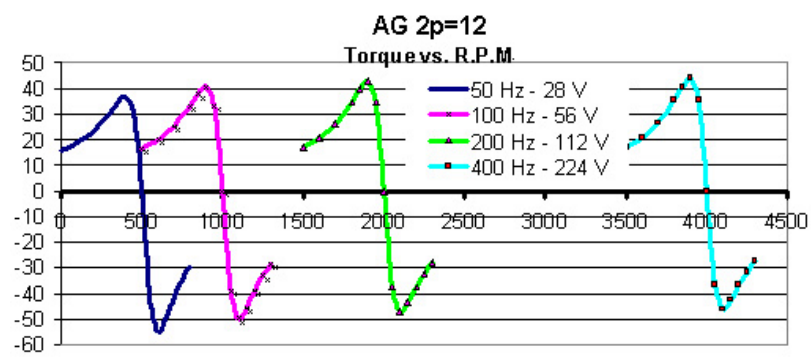

Fig. 4 The AG from Fig.2 at various speeds with constant flux

Better then slip control is $\Delta \mathrm{n}$ control, because the value of $\mathrm{s}_{\mathrm{Mmax}}$ is frequency dependent (Table III and Fig.4). If for our example $\mathrm{AG}$ at $50 \mathrm{~Hz}$ the value of $\mathrm{s}_{\mathrm{Mmax}}=20 \%$ can be easily received, it will be for the same machine at $300 \mathrm{~Hz}$ six times less (Table III.), because:

$$
S_{\text {Mmax }}=\frac{R_{2}^{\prime}}{X_{k}}=\frac{R_{2}^{\prime}}{2 \pi \mathrm{fL}_{k}}
$$

It should be noted, that $\Delta \mathbf{n}$ is the real slip in absolute value, but from historical reasons only its rated value related to fix frequency, $\mathbf{s}=\Delta \mathbf{n} / \mathbf{n}_{1}$ is well-known and used.

TABLE III. Frequency dependent slip predicts constant $\Delta \mathbf{n}$ frequency control

\begin{tabular}{|c|c|c|c|c|c|c|c|c|}
\hline $\mathbf{f}$ & {$[\mathrm{Hz}]$} & $\mathbf{5 0}$ & $\mathbf{1 0 0}$ & $\mathbf{1 5 0}$ & $\mathbf{2 0 0}$ & $\mathbf{2 5 0}$ & $\mathbf{3 0 0}$ & $\mathbf{3 5 0}$ \\
\hline $\mathrm{S}_{\mathbf{M m a x}}$ & {$[\%]$} & 20 & 10 & 6,66 & 5 & 4 & 3,33 & 2,85 \\
\hline $\mathbf{s}_{\mathbf{n}}$ & {$[\%]$} & $\mathbf{5}$ & $\mathbf{2 , 5}$ & $\mathbf{1 , 6 6}$ & $\mathbf{1 , 2 5}$ & $\mathbf{1}$ & $\mathbf{0 , 8 3}$ & $\mathbf{0 , 7 1 2 5}$ \\
\hline $\mathbf{n}_{\mathbf{1}}$ & {$[\mathrm{RPM}]$} & 500 & 1000 & 1500 & 2000 & 2500 & 3000 & 3500 \\
\hline $\mathbf{n}$ & {$[\mathrm{RPM}]$} & $\mathbf{5 2 5}$ & $\mathbf{1 0 2 5}$ & $\mathbf{1 5 2 5}$ & $\mathbf{2 0 2 5}$ & $\mathbf{2 5 2 5}$ & $\mathbf{3 0 2 5}$ & $\mathbf{3 5 2 5}$ \\
\hline $\boldsymbol{\Delta} \mathbf{n}$ & {$[\mathrm{RPM}]$} & \multicolumn{10}{|c|}{$\mathbf{2 5}$} \\
\hline
\end{tabular}

For the same torque at any speed and frequency the value of $(\mathbf{f} . \mathbf{s}) \approx \Delta \mathrm{n}$ is constant and from measured AG speed can be converter frequency continuously estimated as follow:

$$
f=\frac{p}{60}(n-\Delta n) \quad M=\text { const }
$$

It is in good agreement with the calculation of rated rotor losses (Joule). If the power increase is given only by the voltage component at the same current, the rotor winding losses must be speed independent

$$
\Delta P_{2}=3 \cdot R_{2}^{\prime} \cdot I_{2}{ }^{2}=\text { const }
$$

and from the function

$$
\Delta \mathrm{P}_{2}=\mathrm{s} . \mathrm{P}_{\delta}
$$

the slip must decrease with increasing output power (Table III.).

\section{B. AG control}

The asynchronous motor can convert to the generator at constant frequency supply, when its speed becomes higher, then the speed of stator field (Fig.3). Then the stator current grows up again, but it moves into 4-th quadrant (Fig.8) and the power orientation is revolved. At any speed the asynchronous machine can work as AG, if it is supplied by variable frequency, which creates the stator field speed slower, then the rotor's one is.

At the constant rotor speed $\mathbf{n}$, for half-power reduction, the torque must be reduced from $\mathrm{M}_{1}$ to $\mathrm{M}_{2}$ (Fig.5). It is possible either by frequency change from $f_{1}$ to $f_{2}$ with constant voltage, or at the same frequency $f_{1}$ by voltage reduction to $\mathrm{U}_{2}$. In the first case it brings smaller slip and high flux, in the second higher slip losses, but consequently smaller iron losses thanks reduced flux. Total losses optimizing by voltage and slip variation is the aim of the next.

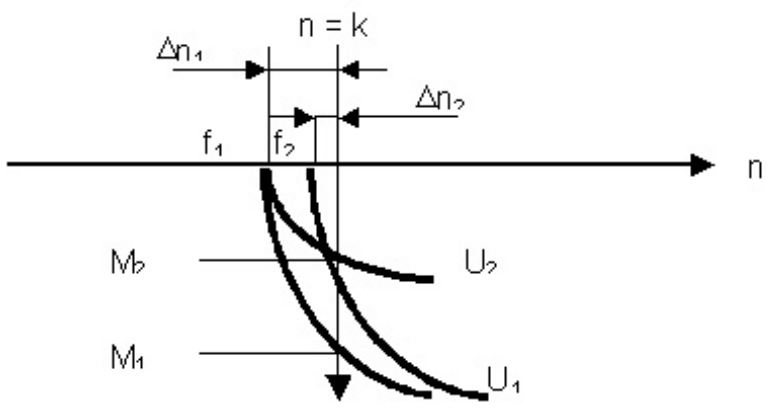

Fig.5 Power reduction of $\mathrm{AG}$ at constant speed by voltage or frequency

\section{VSCF Diesel GEN-SET}

The first models of variable speed power sources were mostly designed with synchronous generator (SG) and because the field control is not necessary in this application, the permanent magnet (PM) excitation was used with advantage. Such generator (PMSG) reaches best efficiency (with full load), but it is very expensive in manufacture and its PM from rare earth are very sensitive to higher temperature. Passive rectifier is the advantage in acquisition price, but DC/DC step-up converter must complete it (Fig.6); which represents another block of energy conversion and additional losses in compare with active pulse rectifier. Also non-sinusoidal current from generator to diode rectifier causes additional losses in armature winding.

The power conversion is obligatory, for constant frequency output but attached frequency converter decreases the total efficiency. Therefore all components 
of power flow must be carefully optimised to reach better parameters then in constant speed generation.

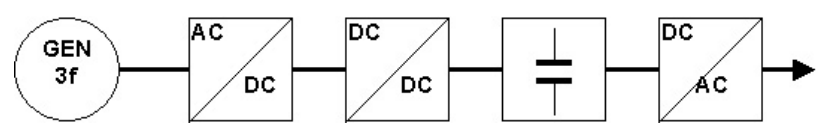

Fig.6 Frequency converter with diode rectifier must have additional DC/DC converter bloc

The variable voltage and frequency of generator is in the first block of converter inverted to the constant value DC voltage in inter-circuit (Fig.1). Having the inverter bridge in the function of active front-back rectifier (Fig.2), the asynchronous generator (AG) can be used too, with many advantages (mechanical and thermal strength, low price, good market offer, simple control etc.). Its only one disadvantage is its rotor winding (cage) joule losses in addition, which are slip dependent, but it can work with reduced flux density and reduced iron losses consequently with optimal slip (and voltage) to reach comparable efficiency oppositely to PMSG.

\section{A. AG versus PMSG}

The advantage of synchronous generator with permanent magnets (PMSG) is its highest efficiency because of no rotor losses. Oppositely the asynchronous generator (AG), with the same stator dimensions and the same flux density in the air gap, has thanks the magnetizing current component higher stator current (always with inductive power factor) at equal output power. But moreover it has the slip losses in the rotor winding (Fig.7).

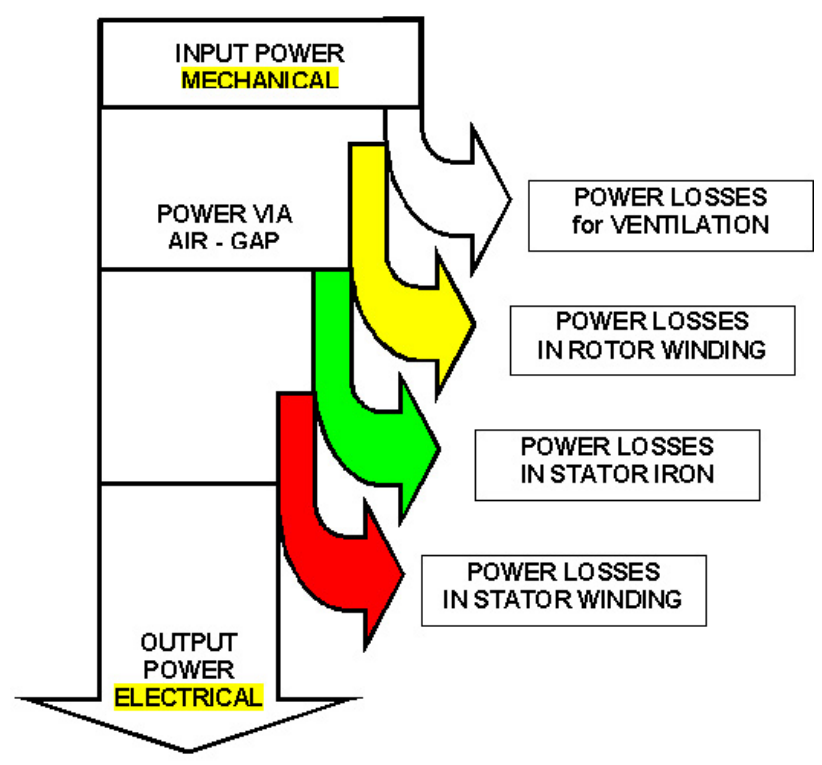

Fig.7 Power flow diagram of AG

There are also some disadvantages of PMSG, which must be taken into account. First it is constant flux at any load, which is not optimal at low power. To minimize total losses there is better some small flux (and voltage) decrease with consequent important iron losses reduction, and only little current (and joule losses) increase. AG flux control is very easy.
Then it is operating frequency, which is much higher for PMSG. For typical driving speed $3000 \mathrm{rpm}$ the common 4-pole AG works with frequency about $100 \mathrm{~Hz}, \mathrm{PMSG}$ because of the PM stability [8] must have at least 10poles with frequency $250 \mathrm{~Hz}$, or better 12 poles with frequency $300 \mathrm{~Hz}$.

Inverter control of SG must be much more precise to keep the SG in synchronism. Also the price of SGPM appears to be its disadvantage, as well as its low thermal strength, which needs better rotor ventilation.

\section{B. Numerical model of $A G$}

The main purpose of this work is to find some possible control rule with non-constant $\Delta \mathrm{n}$ for variable speed and power input to minimize total AG losses. The numerical model of AG was therefore prepared to optimize the efficiency. The computational method of optimal slip estimation for given values of mechanical power and speed will be presented later.

The calculations are based on slip variation and sequential evaluation of all losses components, which are subtracted from mechanical power input. The resulting electrical power output maximum gives the right value of slip and stator frequency for any speed and power (or torque) input.

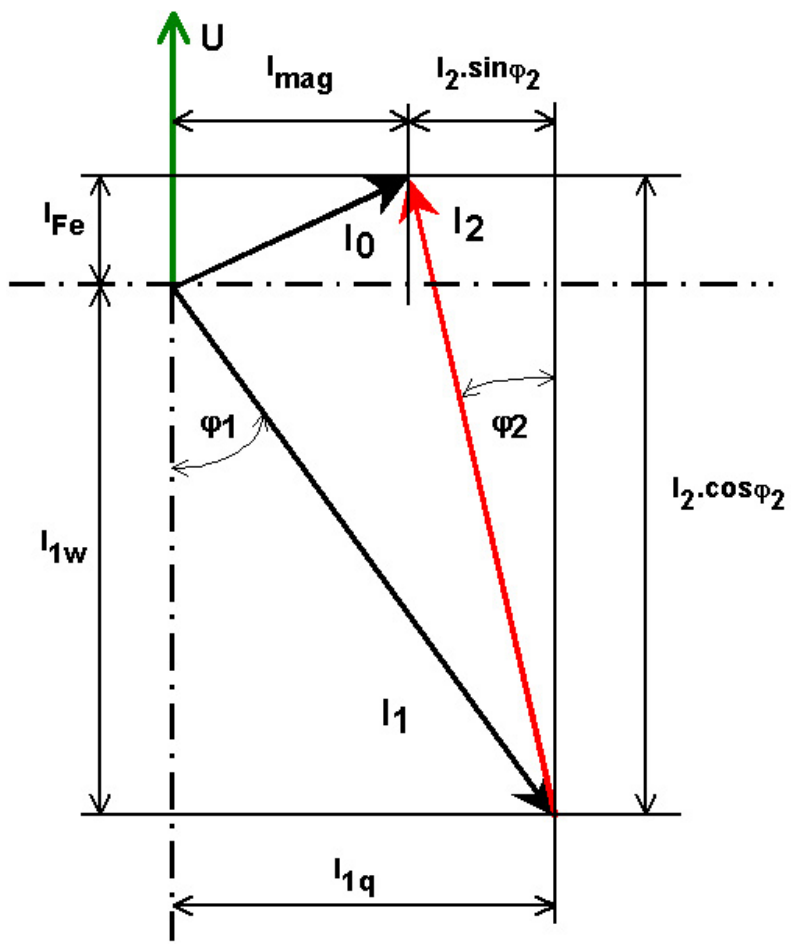

Fig.8 Vector diagram of AG

The common simple method of power control based on constant slip ( $\Delta \mathrm{n}=$ const.) used in electrical drives for asynchronous motors braking [9] gives not optimal output power. The frequency is calculated from the measured rotor speed and $\Delta \mathrm{n}$, which is usually equal to nominal value:

Then the frequency is:

$$
\Delta \mathrm{n}=60 . \mathrm{f} / \mathrm{p}-\mathrm{n}_{\mathrm{n}}
$$

$$
f=p(n-\Delta n) / 60
$$


versus input power with constant speed parameter is in Fig.14.

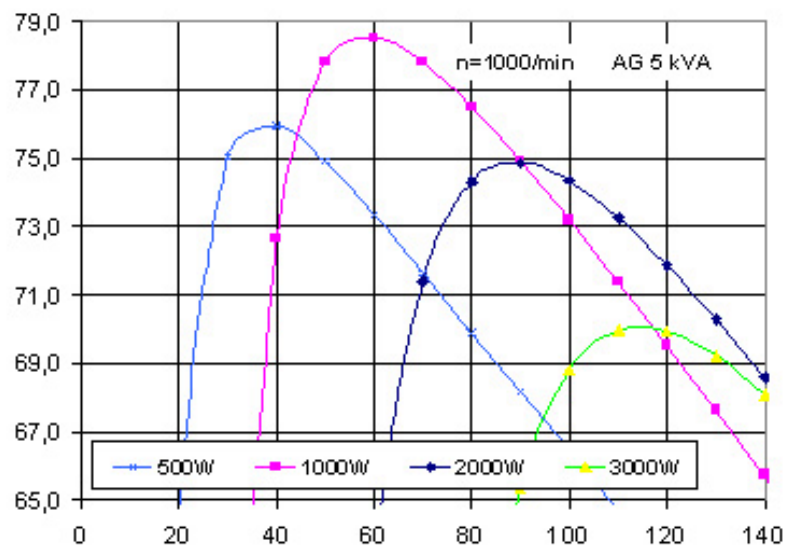

Fig.12a AG efficiency [\%] vs. slip $\Delta \mathrm{n}$, at $1000 \mathrm{RPM}$

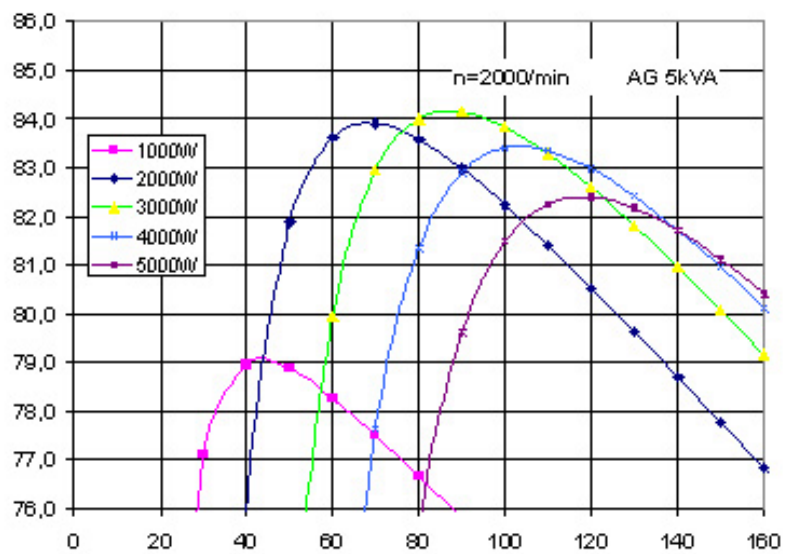

Fig.12b AG efficiency [\%] vs. slip $\Delta$ n, at 2000 RPM

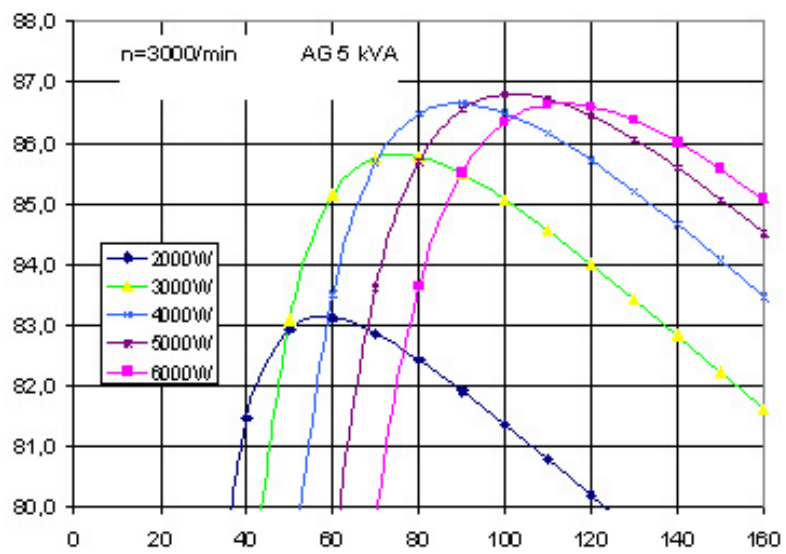

Fig. 12c AG efficiency [\%] vs. slip $\Delta$ n, at 3000 RPM

The comparison of AG vs. PMSG efficiencies can be done from Fig. 15 and 16. The PMSG is only hypothetical with the same number of poles, the same armature winding with no loss in its rotor. The rotor is so PM equipped to create field, which induce nominal voltage at nominal frequency. It is not the optimal construction and this is the reason of so bad PMSG results.
U [V] vs. $n$ [RPMI] (AG optimal efficiency)

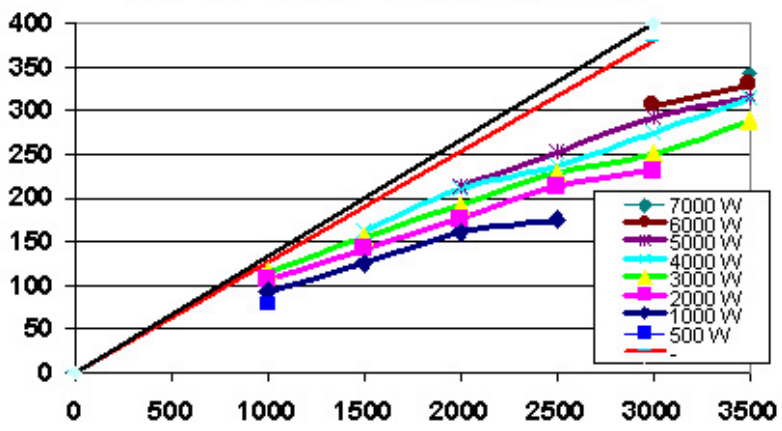

Fig.13 Output voltage regulation of optimised AG

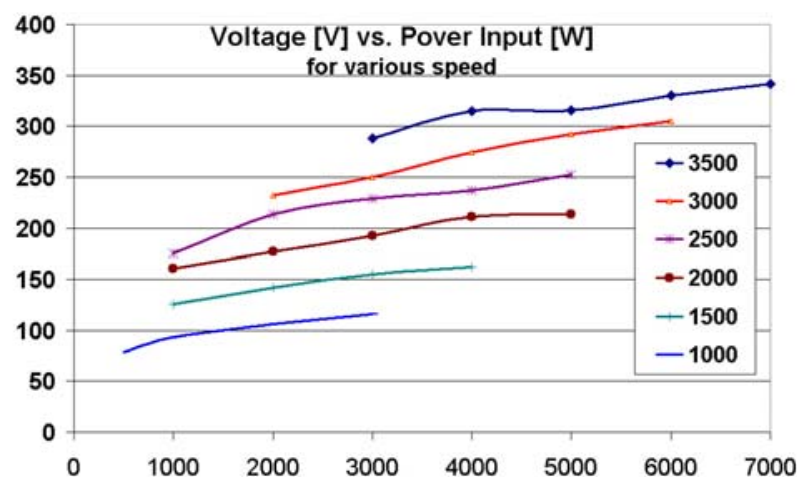

Fig.14 Output voltage of optimised efficiency AG

ETA [-] ws. in put POWER [W] AG variable Flux

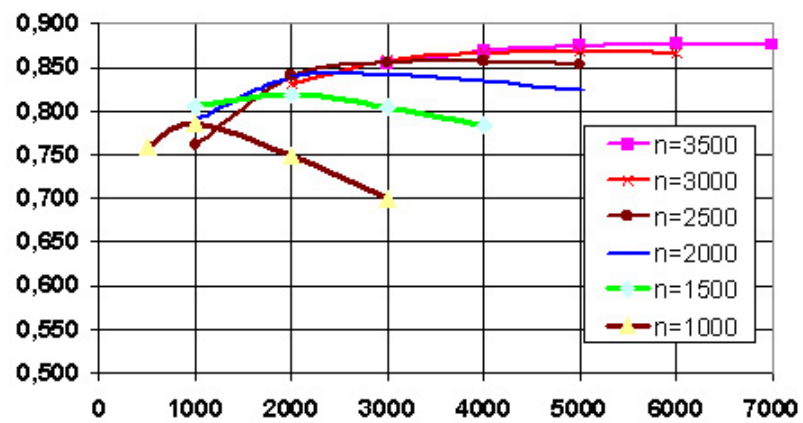

Fig.15 AG optimal efficiency

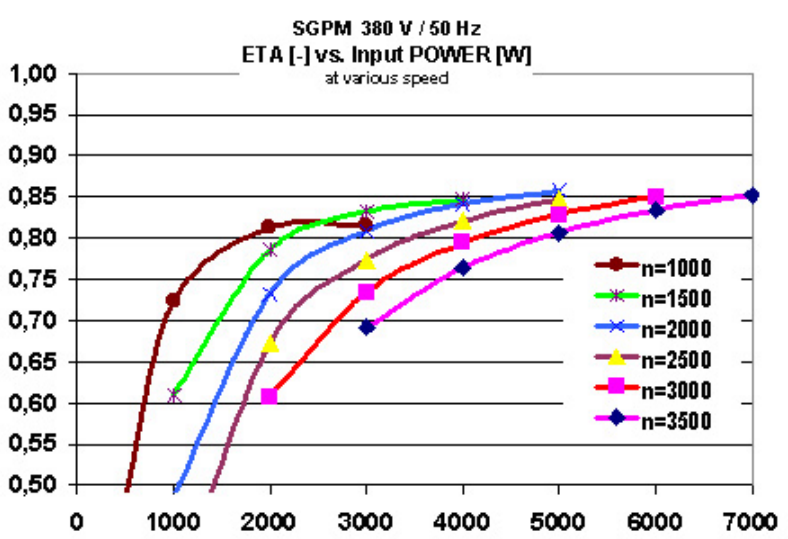

Fig.16 Efficiency of SGPM with AG equal parameters 
AG power factor is highly surprising (Fig.17), because the flux reduction reduces also the reactive component of current. From this analysis results, that practically no joule losses rise will appear due to power factor.

$\cos$ FI 1[-] vs. Input POWER [W] $A G$ variable Flux

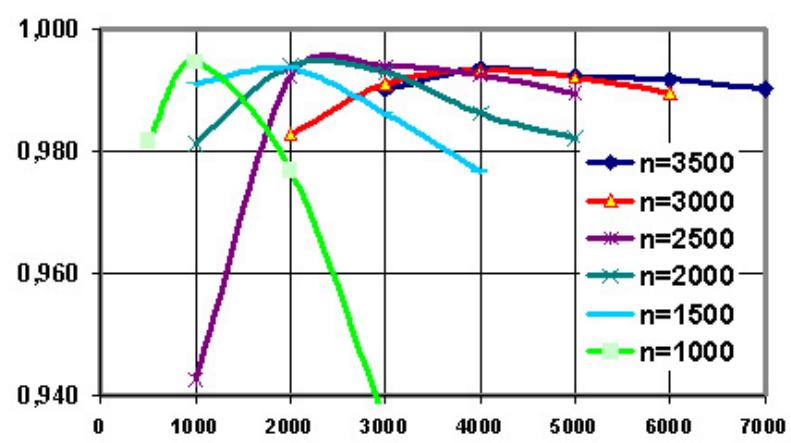

Fig.17 Power factor of optimised efficiency AG

Speed reduction brings worse ventilation and heat transfer, total losses are also decreased but constant current means constant copper losses in armature winding. The AG in wind power generation has no problem, in Diesel driven GEN-SETS must be current observed too, and this dependence can be seen in Fig.18.

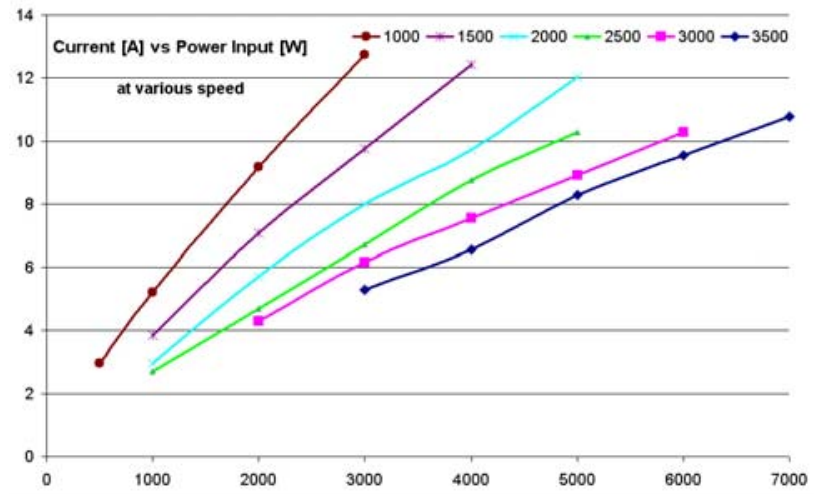

Fig.18 Current from optimised efficiency AG

\section{A. AG choise}

One of AG advantages is its price and wide choice on market. All asynchronous motors (AM) can work as generator without any special requirements for torque curve shape, because AG always works near to synchronous speed.

To right dimensioning it is important not forget the fact, that on the AM label is its mechanical power output. Electrical input power is in the size range, which is interesting for small power sources $1-20 \mathrm{~kW}$, about $15 \%$ more (Table IV) and on the shaft of AG it is next $15 \%$ power more from driving engine. A $7 \mathrm{~kW}$ Diesel can drive AG with electric output over $6 \mathrm{~kW}$ with label power $5,5 \mathrm{~kW}$.

For higher frequency AG needs only better rotor balance. If four-pole $\mathrm{AG}$ is driven by $3000 \mathrm{RPM}$ its frequency will be $100 \mathrm{~Hz}$ and with delta-connected stator winding there is no more remake necessary. AM 5,5 kW $2925 \mathrm{~T}, 400$ $\mathrm{V} / \mathrm{Y}$ can be so replaced by AM $3 \mathrm{~kW}, 1400 \mathrm{~T} 220 \mathrm{~V} / \mathrm{D}$ and it is only slightly demagnetized machine from bulk production.

TABLE IV. Survey of two-pole bulk AM

\begin{tabular}{|c|c|c|c|c|c|c|c|c|}
\hline Pmot & $\begin{array}{c}\text { ETA } \\
\text { mot }\end{array}$ & $\begin{array}{c}\text { P1mot } \\
=\text { P2gen }\end{array}$ & $\Delta \mathrm{P}$ & $\mathrm{P} 1 \mathrm{G}$ & $\begin{array}{c}\eta \\
\text { GEN }\end{array}$ & $\mathrm{I} 1$ & $\cos \varphi 1$ & $\mathrm{n}$ \\
\hline $\mathrm{W}$ & $\%$ & $\mathrm{~W}$ & $\mathrm{~W}$ & $\mathrm{~W}$ & $\%$ & $\mathrm{~A}$ & --- & $\mathrm{RPM}$ \\
\hline 1500 & 79,0 & 1899 & 399 & 2297 & 82,6 & 3,22 & 0,85 & 2860 \\
\hline 2200 & 82,0 & 2683 & 483 & 3166 & 84,7 & 4,55 & 0,85 & 2880 \\
\hline 3000 & 84,0 & 3571 & 571 & 4143 & 86,2 & 6,06 & 0,85 & 2890 \\
\hline 4000 & 86,0 & 4651 & 651 & 5302 & 87,7 & 7,80 & 0,86 & 2905 \\
\hline 5500 & 86,5 & 6358 & 858 & 7217 & 88,1 & 10,31 & 0,89 & 2925 \\
\hline 7500 & 88,0 & 8523 & 1023 & 9545 & 89,3 & 13,82 & 0,89 & 2930 \\
\hline 11000 & 89,5 & 12291 & 1291 & 13581 & 90,5 & 20,15 & 0,88 & 2940 \\
\hline 15000 & 90,2 & 16630 & 1630 & 18259 & 91,1 & 26,66 & 0,9 & 2940 \\
\hline
\end{tabular}

\section{Car board-net sources}

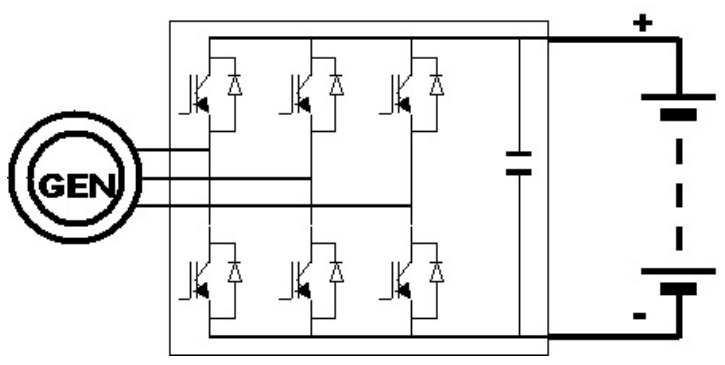

Fig.19 Car board net power source based on AG

Maybe it is a little out of topic, but mostly used variable speed generators are car alternators. The big advantage of $\mathrm{AG}$ in here is its much simple rotor and continuous presence of accumulator battery means no trouble with inverter initialization. Only the price of inverter is limiting now, but generally the prices of electronics are rapidly decreasing and in few years the car supply will be realized by $\mathrm{AG}$ as is in Fig.19 or, may be with higher torque and power only one combined machine will serve as generator and starter.

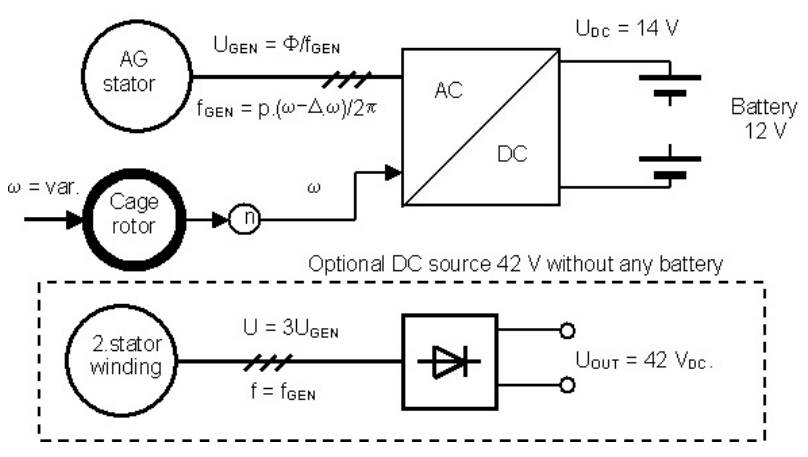

Fig.20 Two voltage nets source based on AG

Twin windings system can be designed to supply two isolated board circuits of different voltage (14 V and 42 $\mathrm{V}$ respectively) with only one control of the primary one, 
which is battery connected [3]. The second one has stabilized voltage and supplies simple diode bridge (Fig.20). Survey of voltage, current frequency and flux in all the speed range is clearly from Table $\mathrm{V}$.

TABLE V. AG flux decrease for constant power output

\begin{tabular}{|rc|c|c|c|c|c|c|c|c|c|}
\hline $\mathrm{n}$ & {$[\mathrm{rpm}]$.} & 800 & 1200 & 1600 & 2000 & 4000 & 6000 & 8000 & 10000 & 12000 \\
\hline $\mathrm{f}_{\max }$ & {$[\mathrm{Hz}]$} & 80 & 120 & 160 & 200 & 400 & $\mathbf{6 0 0}$ & $\mathbf{8 0 0}$ & $\mathbf{1 0 0 0}$ & $\mathbf{1 2 0 0}$ \\
\hline $\mathrm{U}_{\text {GEN }}$ & {$[\mathrm{V}]$} & 8 & 12 & 16 & 16 & 16 & 16 & 16 & 16 & 16 \\
\hline $\mathrm{I}_{\operatorname{maxGEN}}$ & {$[\%]$} & \multicolumn{10}{|c|}{100} \\
\hline $\mathrm{I}_{\operatorname{maxNET}}$ & {$[\%]$} & 50 & 75 & \multicolumn{10}{|c|}{100} \\
\hline$\Phi / \Phi_{\max }[\%]$ & 100 & 100 & 100 & 80 & 40 & 26 & 20 & 16 & 15 \\
\hline
\end{tabular}

\section{Conclusion}

The model results are in good agreement with theoretical expectations, the laboratory verification is not still completed. First laboratory test are oriented to the voltage control in inter-circuit and starting of inverter without $\mathrm{AC}$ net on the output side.

All here presented result are only for one two-pole AG, which is not optimal for low speed applications, but it was to disposal in our laboratory and it can work with our Diesel. The next models are supposed to be realized from four and six poles machines respectively, with reduces power, where better efficiency is supposed.

The parameters of standard asynchronous machines, which are published by manufacturers for customers, are not sufficient for the presented model input. Some of them must be reached by laboratory tests or received from designer's calculations.

The comparison with SGPM has been realized only in the simplified version of hypothetical machine with equal stator.

Our laboratory model new frequency converter consists from two identical professional inverter units connected in their DC inter-circuits (Fig.2). The vector control can be used too without any speed loop and torque control derived from inter-circuit voltage is still verified.

Asynchronous generator offers high enough efficiency for the use in variable speed generating. It is much more cheep and robust then PMSG and its control in active back front converter is more simple. The rotor cage can be operated at much higher temperature then $\mathrm{NdFeB}$ magnets. The only one disadvantage is very narrow airgap, which needs strong shaft and perfect bearings.

In the automotive industry the AG can offer the brushless generator with higher reliability. AG can also be used in development of gearless starter-generator unit with simple inverter or in new board net systems with two voltages. The low voltage AG can be manufactured with small adaptations in technology of actual alternators, the necessary converter with MOSFET is also very simple and technology becomes cheaper and more reliable from year to year.

The complete problem of ventilation and heat transfer is not solved in here; the Joule losses thanks very high power factor are better then supposed, and iron losses reduction can be solved successfully.

\section{Acknowledgement}

The above research work is supported by the Grant Agency of Czech Republic (Project No. 102/03/0795).

\section{References}

[1] Knitterscheidt,H.: Neue Generation SEA (Stromerzeugungsaggregaten) für militärische Nutzung. In: „Moderne elektrische Energietechnik einschließlich Elektrochemischer Energiequellen“. Bundesakademie für Wehrverwaltung und Wehrtechnik Mannheim (SRN), May 1998

[2] Kurka, O. - Bršlica, V.: The Concept of 3rd Generation Mobile Electrical Power Sources. Proceedings of ERK'99, Portarosa, Slovenia, 1999 vol.A, pp. 375 - 378

[3] Bršlica,V.: The Wide Range Speed Asynchronous Generator, in Proceedings of X. ISEM 2002, CVUT Prague, Sept.2002 pp.155-160 ISBN 80-01-02617-5

[4] Bršlica,V.: The Variable Speed Power Generating System Conception. ELEKTRO 2001, Žilina, Slovakia, 5/2001 pp. 65-70 ISBN 80-7100-836-2

[5] Bršlica,.: Napět'ové měniče pro generátory $\mathrm{s}$ proměnnými otáčkami, Proceeding of SYMEP '02, TU Liberec, June 2002

[6] Winkler, J.: Usměrňovač s pulsním řízením In: Elektro 2/1998 pp. 3-7

[7] Melichar, M.: Asynchronní generátor jako zdroj elektrické energie. Proceedings of EC 98. VA Brno1998, pp. 111 - 118

[8] Bršlica,V. - Kurka,O. - Melichar,M.: Optimal rotor for PM generator, Proceedings of WSEM 2000, CVUT Prague, Sept. 2000

[9] Červinka,D. - Vorel,P.: Elektrický skútr s asynchronním motorem, Proceedings of EPVE 2001, VUT Brno, Oct. 2001, pp. 196 - 201

[10] Bršlica,V., Tincq,L.: Variable Speed Asynchronous Generator Optimal Efficiency, in Proceedings of XI. ISEM 2003, CVUT Prague, Sept. 2003 pp.155-160.

[11] Bršlica,V.: Možnosti dalšího rozvoje elektrocentrál. In: Proceedings of conference EC'98. VA - Brno FLaPVO, April 1998

[12] Kurka,O. - Melichar,M. - Drtil,J.: Generators for vscf mobile electrical generating sets, Proceedings of SME 2003, Gdansk, Poland, August 2003 